\title{
Opinion
}

\section{Sharing Economy: Promote Its Potential to Sustainability by Regulation}

\author{
Xufeng Liu and Hongmin Chen * \\ Department of Environmental Science and Engineering, Fudan University, Shanghai 200433, China; \\ liuxufeng@fudan.edu.cn \\ * Correspondence: chenhongmin@fudan.edu.cn
}

Received: 8 January 2020; Accepted: 21 January 2020; Published: 27 January 2020

\begin{abstract}
The sharing economy is an emerging economic form with the potential to promote sustainable development; it is highly malleable but tends to not be environmentally friendly or necessarily lead to saving resources. Therefore, to give it the inherent logic of sustainable development and realize its great potential, the sharing economy must be made to meet the necessary conditions and be appropriately regulated in the current window of opportunity. This paper proposes that the potential factors of the sharing economy that can promote sustainable development are mainly improving resource utilization efficiency, market impetus and plasticity and transforming consumption patterns and concepts, while the main limiting factors are the excessive demand that is likely to result from to the descending consumption threshold, lack of maintenance motivation due to the sharing of property rights, and uncertainty in the proportions of increased welfare levels and resource consumption. Then, the paper explores the necessary conditions to promote sustainable development in the sharing economy, namely, the required characteristics of shared products and the need to place constraints on consumers. Next, it discusses how to incorporate these conditional factors into the regulatory framework for the future development of the sharing economy and proposes overall principles and ideas for the governance and regulation of producers, consumers, and platform operators in the operation of and participation in the sharing economy. Finally, the paper emphasizes that the line of regulatory thinking should change because the sharing economy differs from traditional economic forms, and it also emphasizes the importance of exploring conditions and explores the related research prospects for studying regulation with environmental sustainability as the regulatory objective.
\end{abstract}

Keywords: sharing economy; sustainable; potential factors; limiting factors; conditions; regulation

\section{Introduction}

As an emerging economic form covering a wide range of industries, the sharing economy has grown to a considerable scale in the global market, especially in China's market. It has also maintained a relatively high growth rate, becoming the most active area of economic growth at present. In 2018, the market transaction volume of the sharing economy in China reached 294.2 billion yuan, which was an increase of $41.6 \%$ over the previous year. That year, the number of participants in the sharing economy in China was approximately 760 million. The number of people participating in providing sharing economy services was approximately 75 million, which was an increase of $7.1 \%$ over the same period. The number of employees was 5.98 million, which was a year-on-year increase of $7.5 \%$ [1]. According to data from a PwC consulting analysis; by 2025, the sharing economy may increase its total global revenue to USD 335 billion [2].

With the continuous expansion of the scale of the sharing economy and its continuously growing influence over all economic activity, the sharing economy has gradually become a popular area of 
research all over the world. In the past decade, the number and frequency of studies on the theme of the "sharing economy" have increased each year $[3,4]$. In general, the business models, motivations for participation, behavioral preferences of consumers, behavior of economic subjects [5,6], and construction of theoretical systems [7] of the sharing economy remain popular research areas related to the sharing economy [8]. However, with the development of this research, foreign studies have gradually turned to assessing the environmental benefits [9-11], sustainable conditions, and policies for governance and regulation [12,13] of the sharing economy.

As a new economic form with environmental sustainability potential $[7,14]$, the sharing economy can be an important entry point for exploring and researching the effective promotion of sustainable development. Although the definition of the sharing economy is still controversial among different researchers, the main features of the sharing economy can be characterized by online platform, idle capacity, collaborative consumption, non-ownership, accessibility of share, trust and network-based activity and for-profit activities [10], which are significantly different from the traditional economic form. In a broad understanding, the sharing economy is a business model designed to provide convenient and cost-effective access to take advantage of underutilized or redundant resources provided by digital platforms [15]. While the sharing economy has had an impact on the traditional economic model, such as a huge innovation due to disruptive technologies [16], it is often accused of permitting improper competition because of its lack of regulation. With the development of the sharing economy, the demand for guidance and regulation is growing [10]. As a new economic form, in this window of opportunity to develop regulations, the question of whether the sharing economy can embody the concept of sustainable development will be important.

In general, sustainability means the developments meet the present use demand while causing little harm to set the future at play [17]. As for the environmental aspect of sustainability [18], its perennial challenge has been the difficulty of practicing it in reality. For both sustainable production and sustainable consumption, practices are required [7] that only the improvement of existing production and consumption patterns after consideration of the environmental impact will bring sustainability, but the production and consumption systems have strong operational inertia. The path to promoting sustainable production and consumption is currently just adding environmentally friendly regulations and governance $[12,19,20]$ to the existing regulatory system. Although some progress has been made, such as the development of cleaner production and circular economy [21,22], it has not fundamentally changed the traditional mass production, mass consumption, and mass production-consumption patterns in the traditional materialist consumption mode [23]. The traditional production-consumption-formed technology-institutional complex has strong inertia and locking effects.

The sharing economy is different in that it does not originate from environmentally friendly considerations. It results from natural choices driven by consumer rationality with the support of information technology. Therefore, it can be considered somewhat natural to the process of economic development. Of course, its emergence has also encountered considerable resistance due to its impact on existing economic development rules and institutional systems. For instance, when Uber and Didi (a platform for mobility sharing) started in China, they were boycotted by many traditional taxi drivers in some cities. Taxi drivers complained that their financial interests were violated as consumers were attracted by the convenience and relative lower price offered by such online platforms [24]. This is inevitable in the process of interest adjustment, but the sharing economy clearly has many supporters among consumers. Therefore, its speed of development has been amazing, and it has become necessary to consider how to form a technical-institutional complex that is compatible with this new form. The sharing economy will systematically change the existing production and consumption system, and now is the window of opportunity to establish shared economic regulation. In this window, making the concept of sustainable development the internal logic of the sharing economy, rather than restricting its role to marketing, is the necessary consideration for research on regulating the sharing economy, and it is also key to whether sustainable development can be practiced effectively. 
Therefore, this paper will explore the conditions for promoting the concept of sustainable development of the sharing economy. It will examine the positive and limiting factors of sustainable development currently embodied in the sharing economy, and how to incorporate these conditions into the research framework and guidance for regulation of the future development of the sharing economy. The rest of the paper is organized as follows. Section 2 proposes the potential factors for sharing economy to sustainability, while Section 3 proposes the limiting factors. Since the nature of resource-saving and environmentally friendly is not inherent and inevitable in the sharing economy, conditions for the sharing economy to sustainability are analyzed in Section 4, which includes aspects of requirements on characteristics for shared products and services, and constraints for consumers participating in the sharing economy. In Section 5, overall principles and ideas for governance and regulation of producers, consumers, and platform operators and guidelines for government regulators are discussed. The last section present conclusions and avenues for further research.

\section{Potential Factors for Promoting Sustainability}

Reducing the use of resources and promoting changes in consumption patterns are considered to be important potential factors for the sharing economy to promote sustainable development. The sharing economy emphasizes "use" rather than "ownership". This characteristic of this economic form not only allows the full reuse of limited resources, but more importantly, it can promote changes in consumption and thereby the transformation of the production-consumption system and form an endogenous market driving force.

\subsection{Improving Resource Utilization Efficiency and Promoting Resource Conservation}

Sharing idle products will increase the efficiency of resource utilization, which can help reduce the production of products to promote resource conservation [12] and promote more effective allocation and the utilization of resources in the entire society [25]. Additionally, with sharing, as consumption increases, the resource demand increases disproportionately [26], which is a feature that makes sharing sustainable.

\subsection{Market Impetus and Plasticity}

Compared to the sharing economy, after decades of development, these traditional forms of sustainable development have become more mature in their production methods, and their corresponding production, operation and supervision systems have been fully formed. It promotes starting from the back end of environmental regulations in designing production regulations, reducing the negative environmental impact of production and consumption. However, in these forms of practice, there are also corresponding problems; as a result of which, they lack a certain completion motivation and fail to fully achieve the expected results. The main problems are the price and cost barriers in these forms of practice [21] and the lack of market-driven mechanisms [22]. Compared to these mature and systematic practices, the sharing economy, as a new practice model that can implement the concept of sustainable development, is characterized by a change from the consumer side and a transformation from the consumer demand to innovation in production models and concepts of enterprise. The behavior of enterprises will be guided more by the market rather than the simple acceptance of the requirements of government and laws. This will enable the continued sustainability of economic operations while achieving environmental sustainability goals. At the same time, the brand-new practice form makes the sharing economy more malleable, and the impact and resistance of the existing economic operation mode and the formed industrial structure are minimal, enabling the promotion of environmental sustainability through regulation.

\subsection{Promoting Changes in Consumption Patterns and Ideas}

The shift in consumption concepts and motivations brought about by the sharing economy from the demand for the "product" itself to the "service" provided by products will promote the 
sustainability of the entire production and consumption chain. The new consumption pattern caused by the sharing economy can promote massive changes in consumption habits [5] and people's lifestyles and consumption levels [27], and only by changing our lifestyle and consumption levels can humans reduce resource consumption [28], which solves the problem of excessive resource consumption. Internet-based communication [28] and the widespread use of Internet platforms in the sharing economy can help consumption patterns and habits to develop more rapidly and profoundly.

The traditional economic growth model starts by stimulating and inducing people's consumption demand and then supports a huge production system. In this pattern, consumers always keep their satisfaction and achieve happiness by constantly purchasing new goods [29] even though sometimes they do not have such practical demands. To continuously promote the cycle of production-consumption, inefficient use and accelerated abandonment become the norm in the entire system. Consumption is often oriented toward expansion, beyond practicality, causing tremendous pressure on the resource and environmental systems [23] and forming a so-called "frugal paradox". However, the sharing economy abandons "ownership" for a "use"-oriented consumption logic, provides consumers with more purchasing options [30] without burden of ownership and reducing transaction costs [31] than traditional products, and makes consumers rethink their purchase behaviors and actual demand, leading to consume with a sense of purpose [23,32], which makes consumption return to practicality and reduces the threshold of consumption to take utility as a consideration. Under this logic, consumers can increase their utility by consuming the services undertaken by the shared products to satisfying their real needs rather than constantly buying new goods so that excessive consumption can be avoided, while producers and platform operators can provide consumers with truly efficient services rather than with more brand new products. The sharing economy can contribute to reduce environmental impacts in such regard.

\subsection{Other Potential Factors}

In addition, there are larger numbers of smaller individual interactions in the sharing economy that can bring more flexibility, economic vitality and innovation [26]. Sharing can also help increase consumer utility and increase productivity and economic efficiency, which have positive external effects on society [25]. These factors make the sharing economy an important contribution to promoting sustainable development.

\section{Limiting Factors}

The actual environmental impact of the sharing economy is still uncertain. It does not naturally lead to the reduction of resource consumption and greater environmental benefits. The assertion that the sharing economy is inherently sustainable is unfounded [33,34]. Some researchers even argue that the sharing economy is only a concept taken advantage by entrepreneurs for economic self-interest rather than for sharing [35], where it is unlikely to drive a transition to sustainability [34]. There is no definitive evidence the sharing economy form can minimize consumption [9].

The main factor limiting the ability of the sharing economy to promote sustainable development is the "abuse" problem brought about by the sharing of property rights. This "abuse" can be an additional overconsumption demand that may be generated by the reduction of the consumption threshold caused by the sharing economy, which is often referred to as the "rebound effect". It can also be the use of the quasi-public goods that the products and services feature, and consumers' careless use accelerates the depreciation loss of products and services. It can also be the careless use of consumers due to the quasi-public nature of the products and services, thus accelerating the depreciation of the products and services.

\subsection{Excessive Demand Due to "Rebound Effect"}

The excessive demand generated by the "rebound effect" is considered an important factor in the lack of clarity regarding the benefits of the sharing economy. Sharing reduces the price of goods 
or services, which may result in consumers without real needs choosing to consume more goods or services because of cheaper prices [27] and an excessive increase in consumption thresholds, resulting in more resources being consumed. At the same time, the concept of "use rather than possession" allows consumers to decide whether to lease rather than purchase goods. For example, sharing increase the travel frequency and length of stay, which likely leads to have a negative impact on environment [36]. Furthermore, much of the transportation and long-distance travel to use the goods may also cause the resulting emissions to offset the positive environmental impacts brought about by sharing.

\subsection{Sharing Products Lack Maintenance Motivation}

Due to the sharing of property rights, the products and services of consumption have the nature of quasi-public goods. In the existing operating mode, consumers lack maintenance power during use. The use of products without care will make the material loss and product wear speed exceed the normal loss rate in the private mode, accelerate depreciation and shorten the life of sharing products. This cycle increases the operating and maintenance costs of the platform enterprise. It may also be necessary to scrap old products and accelerate the production of new products to maintain the normal supply of shared products and services. The resulting increase in resource consumption may offset or even exceed the environmental benefits of the sharing.

\subsection{Uncertain Ratio of Increased Levels of Welfare and Resource Consumption}

Whether the environmental impact of the sharing economy is positive or negative depends on the proportional relationship between the improvement of the overall welfare and the increase in the level of resource consumption when the sharing economy increases consumption. If less increase in the consumption of resources leads to a greater increase in welfare, then such an economic form can be considered to bring environmental benefits. Often, based on common sense, we think that the sharing economy has such a nature that considers its environmental sustainability potential. However, such inferences are not in fact clearly justified, especially for the different types of existing industries. If the level of welfare brought about by the increase in consumption increases, but the processes or the production of new products exceeds the equal proportion of resource consumption and environmental emissions, then environmental benefits will not exist; then, the environmental benefits of the sharing economy will be uncertain.

For example, compared to traditional mobility, sharing mobility attracts consumers to consume more because of higher convenience and lower unit prices. More consumption (longer travel distance) means an increase in consumer welfare, and of course, more resource consumption and environmental emissions. If the marginal resources consumption per unit distance increases more than the marginal increase level of welfare as travel distance increases, the environmental benefits resulting from sharing may gradually disappear. Theoretically, with the increase in the travel distance, the ratio between the increase in the level of welfare and the increase in resource consumption is uncertain. Therefore, regulations are needed to make the marginal increase in resource consumption lower than the increase in welfare in mobility sharing, to ensure its environmental sustainability.

\subsection{Other Limiting Factors}

Environmental considerations do not necessarily translate into consumption behaviors and motivations in the sharing economy [13,37], which may result in uneven distribution of income and increase inequality [33] and even create a highly competitive market that poses a barrier to potential new players. Additionally, there is the possibility of forming an oligopoly [9]. These are all considered limiting factors for the sustainable economic development of the sharing economy.

Ultimately, the sharing economy has the potential to promote sustainable development, but this resource-saving and environmentally friendly nature is not inherent in this economic form; its actual environmental benefits are still uncertain. Regulation will be crucial to realize its potential. 


\section{Preliminary Exploration of Conditions}

The industry sectors involved in the sharing economy are extremely broad and contain a wide variety of goods and services. Given this diversity, it is relatively difficult to use one metric to determine whether all of these sharing economy models produce positive environmental benefits relative to traditional economic models and the extent of any such benefits. Although studies have shown that under specific conditions and modes, car sharing [38], accommodation sharing [39] and books sharing [40] do bring some positive environmental benefits, actually reducing carbon emissions and energy consumption, such accounting is based on specific industries, specific time periods and in a specific study area. However, the industries involved in the sharing economy are extensive, also spanning many time and regional scales. With these challenges and those of developing criteria for quantification and measurement and the set preconditions, the workload and difficulty of comprehensively and reliably assessing the environmental benefits in quantity of the various industries in the sharing economy is enormous.

Admittedly, such assessment and accounting also have certain research significance. However, where it is clear that the sharing economy has the potential to promote sustainable development, it is more important to study the conditions that give the sharing economy environmental sustainability. Such conditions should mainly be based on the characteristics of the sharing products and services themselves (Section 4.1), as well as the constraints on consumers in the activities (Section 4.2) in the sharing economy.

\subsection{Necessary Characteristics for Shared Products and Services}

Durability, compatibility, and renewability are necessary characteristics for sharing products or products carrying sharing services.

\section{- Durability}

One of the key conditions is the durability [12] of the shared products and services. Durability means that products that are put into the sharing market and products that carry sharing services should be high quality and durable, allowing them to withstand more or more intensive use, resulting in longer product life. Planning for the life of a sharing product should strive to allow it to be used as long as possible while fully evaluating the product safety and user experience. By increasing the quality and extending the lives of products, the product life cycle is extended to slow the production of new products and the frequency of placing them in the sharing economy market, thereby reducing the consumption of resources caused by sharing products.

\section{- Compatibility}

Compatibility means that sharing items produced are compatible with the sharing platform. Through development, the same types of products can be compatible with various sharing platforms, and even cross-category products can be compatible with existing sharing platforms, thus avoiding the need for extra resource investment to create new platforms for new types of sharing products. For example, shared bicycles operated by different platforms can be compatible and used on their respective platforms through standardized protocols. For another example, different kinds of shared products produced by different manufacturers can be operated and used on a unified platform. Shared products and services with such compatibility can ensure the environmental sustainability of the sharing economy.

- Renewability

Renewability requires that materials used for the production of sharing products be recyclable [10]. After the product's life cycle is over, the product can be recycled; the recycling can be either whole or as much as possible to produce a new sharing product. Taking shared bicycles as an example, the scrapping of components and their inability to be recycled [41] are an important reason why 
they may lose the environmental benefits from sharing. If the component materials are renewable, new shared bicycles can be produced from them, which may reduce the consumption of resources.

Products and products that carry sharing services that are durable, compatible, and recyclable can minimize the investment and consumption of resources at the level of the product itself for sharing to reduce the offsetting effects of environmental benefits from the sharing economy.

\subsection{Constraints for Consumers}

In the analysis of limiting factors on the sustainable development of the sharing economy, "abuse" by consumers $[9,27]$ brought about by shared property rights is significant. To make the sharing economy sustainable, there must be constraints on consumers in its operation. Through multiparty regulation, consumer demand should remain at the same level or see a reasonable increase, not experience the excessive growth that is generated by the sharing economy. At the same time, in the operation of the sharing economy, relevant mechanisms should be created to solve the problem of consumers' careless use of products resulting in an excessive product use loss rate. Meanwhile, products should be effectively maintained by platform operators, and the consumer demand and sharing product loss rate caused by the sharing economy should be kept at reasonable levels to break through these constraints. Under these conditions, the sustainability of the sharing economy is guaranteed.

\section{Regulatory Principles and Ideas}

\subsection{Existing Research}

At present, exploration of the potential regulation of the sharing economy seeks mainly to ensure its economic growth and the ability to promote innovation [42-44] and to control legal risks [45-48]. At the same time, some scholars have studied corresponding regulations to avoid the negative social impacts brought about by the sharing economy [44,49,50], existing credit risks [50], platform information security risks [51], labor relations risks [52], and so on.

There are relatively few studies on designing sharing economy regulation with environmental sustainability as the regulatory goal. Based on a wide range of regulatory perspectives, Yuan et al. [53] note that to promote economic growth, environmental regulation of industries must fully stimulate technological innovation, encourage enterprises to actively transform the production process, and encourage all types of environmental investments to ensure environmental protection while meeting the needs of economic growth. Specific to the sharing economy, Demailly et al. [12] assert that as long as it begins on a small scale, the sharing economy should be supported by government to enable it to explore new means of ecological transformation. Governments can provide financial support or help incubate sharing economy enterprises through policy guidance. When a sharing economy enterprise exceeds a certain scale, its environmental performance should be analyzed to assess its environmental benefits. At the same time, what specific economic model governments should support is the most important consideration. Setting policies allows companies to incorporate environmental and sustainability goals into their production and development strategies. Similar to Demailly et al. [12] regarding regulatory intervention and the setting of regulatory intensity at each stage, Einav et al. [54] and Ranchordás [43] stress the importance of timing of regulatory interventions and suggest that early-stage regulation should be loose. Leung et al. [55] point out that alignment to mutual interests, collaboration for shared success, and commitment to social responsibility are three strategies for the sharing economy to reach sustainability.

\subsection{Sustainable Development-Oriented Regulatory Principles and Ideas}

The sharing economy tends to reshape established markets or establish new markets. It must break free of the legislative ideas and regulatory models of the traditional economy, build a new legal framework that moves away from traditional concepts, and be given responses beyond traditional 
regulation $[43,49,56,57]$. To give full play to the potential of the sharing economy to promote sustainable development, the regulation of the sharing economy must not only regard environmental benefits as one of the important objectives but, more importantly, it must be more intensive than in the traditional economy.

In the traditional economy, private purchases mean complete property rights, and regulators need only regulate producers, such as setting standards for product quality and environmental impact. However, in the sharing economy, property rights are shared, and as a result, all the entities in the system must be regulated, including producers, platform operators and participants; even government regulators play an important part. The rights and responsibilities of each subject must be redefined. This was previously impossible, but with the development of Internet technology and the construction of a social credit system, such operations became feasible. However, this requires breaking the current technology-institutional complex and creating an overall definition of the sharing economy and the principles of regulation at the macro level. At the same time, collaborative governance style [58] may be applied in that participants including producers, consumers, platform operators and government in the sharing economy need to play well their own role and take good advantage of respective capabilities with the common goal of achieving the sustainability of the sharing economy.

Next, Sections 5.2.1-5.2.3 proposes overall principles and ideas for governance and regulation of producers, consumers and platform operators, and guidelines for government regulators in the sharing economy respectively.

\subsubsection{For Producer Companies}

The products produced by companies for sharing should be durable, compatible and renewable. Companies should ensure product longevity through technical development and improvement based on balancing the safety performance of the product. They should set optimal technical standards and operating instructions so that products can be repaired in cases of partial damage rather than having to be scrapped, and the corresponding technical system can recover the corresponding materials from the respective parts after products are scrapped to produce new product components. The idea of these product characteristics and the entire industry chain from raw material production and procurement to product production to recycling and reproduction are aimed at ensuring environmental benefits of the sharing economy. This requires producer companies to incorporate environmentally friendly and sustainable principles into their own development strategies and production standards, rather than seeking to speed up product changes through changes to production in traditional economies to generate more profit by increasing sales. The transformation and resetting of such corporate strategies and production standards is difficult for businesses to carry out spontaneously in the existing market economy environment. The government must introduce corresponding industrial policies and technical guidelines to regulate them.

\subsubsection{For Consumers and Platform Operators}

The sharing of property rights dilutes consumers' responsibility [12] in the operation of the sharing economy. Due to the quasi-public nature of shared products, consumers themselves lack the maintenance power over the shared products without the constraints of rules. As a result, consumers must have their own sense of responsibility and act accordingly. In the process of regulation, it is necessary to restrict consumers' behavior based on this goal, which can be achieved through regulating operators of shared platforms.

The shared platform operator can use the existing technology to evaluate consumers' behavior, use the construction of the personal and social credit system to restrict consumers' behavior through the credit mechanism, prevent damage (whether from malice or carelessness) to shared products, and, through upgrading technology, judge product damage by consumers and use the appropriate credit or economic punishment mechanism to increase the cost of violation to consumers and help consumers establish a sense of responsibility in the sharing of economic participation. At the same 
time, platform operators must fully study consumer behavior and establish corresponding mechanisms and frameworks through technology to ensure that consumers are at a reasonable level of consumer demand when using shared products or products that share services and avoid long-term use to meet "excessive demand" so that shared products can flow efficiently between consumers; otherwise, the positive environmental effect of "rebound consumption" in the operation of the sharing economy is weakened.

In addition, the sharing platform operator should assume daily maintenance responsibility for the shared product, establish a normal mechanism to carry out regular maintenance, and promptly submit any products needing repair to the producer enterprise for major damage and component loss. Through these initiatives, the life cycle of shared products will be extended. In addition, when sharing platform operators deploy shared products or services across geographical distances, they should seek to minimize the distances traveled from the producers' companies or maintenance centers to the market to minimize emissions.

\subsubsection{For Government Regulators}

As a new economic form, the sharing economy has a reshaping effect on existing markets. It is inevitably incompatible with traditional laws and economic regulation. Government regulators must change their regulatory thinking. Developing in accordance with some of the existing laws and regulations, ultimately, the sharing economy can bring about the improvement of social welfare and become an effective form of sustainable development.

In the early development of a new sharing economy, relatively loose regulation is possible. With the expansion of the economic scale, on the basis of the original laws and regulations governing the traditional economic forms [59], policies and regulations that apply to the sharing economy should gradually expand to fully release its potential. Government regulators must also develop a corresponding framework to form a recognition mechanism for the true form of shared economy, to clarify which industries to support under what conditions and gradually evaluate the environmental benefits of various forms of the sharing economy. Life Cycle Assessment (LCA) can be used to estimate environmental impacts associated with all the stages of the shared product's life [20]. Mechanisms and frameworks that support sharing economy industries that can bring environmental benefits to help promote sustainable development and those that are considered to have no environmental benefits after evaluation can limit their subsequent development and scale expansion after comprehensive consideration. To support shared industries, economic incentives such as tax incentives and financial support, and noneconomic incentives such as development counseling, and aid promotion can be adopted (see Figure 1). 


\begin{tabular}{|c|c|}
\hline For producer companies & For consumers \\
\hline $\begin{array}{l}\text { Producing shared products with } \\
\text { durability, compatibility, and } \\
\text { renewability } \\
\text { Setting technical standards and } \\
\text { operating instructions for components } \\
\text { manufacture, recovering and recycling } \\
\text { Incorporating sustainable and } \\
\text { environmentaly friendly principles into } \\
\text { corporate strategies }\end{array}$ & $\begin{array}{l}\text { Having sense of responsibility and act } \\
\text { accordingly to maintain and use the } \\
\text { shared products carefully } \\
\text { Comsuption based on the real demand } \\
\text { rather excessive comsuption of } \\
\text { products and services because of } \\
\text { cheaper prices supplied by sharing }\end{array}$ \\
\hline For platform operators & For goveronment regulators \\
\hline $\begin{array}{l}\text { Increasing the cost of violation to } \\
\text { consumers and prevent damage } \\
\text { (whether from malice or carelessness) } \\
\text { to shared products } \\
\text { Ensuring shared products can flow } \\
\text { efficiently between consumers to avoid } \\
\text { excessive demand } \\
\text { Assuming daily maintenance } \\
\text { responsibilities } \\
\text { Minimizing the geographical distances } \\
\text { when deploy and transport the shared } \\
\text { products }\end{array}$ & $\begin{array}{l}\text { Changing regulatory thinking } \\
\text { Loosing the regulation in the early- } \\
\text { stage of the new sharing economy } \\
\text { Expanding the regulations apply to } \\
\text { sharing economy with the expansion of } \\
\text { the scale } \\
\text { Developing a framework to clarify which } \\
\text { industries to support and to evaluate } \\
\text { environmental benefits of various forms } \\
\text { of sharing economy, with corresponding } \\
\text { support or limiting policies }\end{array}$ \\
\hline
\end{tabular}

Figure 1. Overall principles and ideas for governance and regulation of producers, consumers, and platform operators and guidelines for government regulators.

\section{Outlook}

As a new economic form under the concept of sustainable development, the sharing economy has the potential to become a more effective form sustainable development in practice, but it does not inherently lead to resource conservation and environmental friendliness. The environmental sustainability of the sharing economy is not inevitable. As an emerging model that is highly malleable and intrinsically motivated, if we can explore the conditions that will lead to its environmental sustainability at this early point when the sharing economy has the potential to produce significant innovation and face little developmental resistance, we can adopt reasonable regulations that enable it to produce environmental benefits while being highly economically efficient; further, it can be used to effectively promote sustainable development. This will achieve a win-win situation between economic development goals and environmental protection goals. Such research will be very significant.

Existing research exploring the environmental impact of the sharing economy is still relatively limited. This paper preliminarily addresses the basic conditions for realizing the environmental sustainability of the sharing economy by sharing the factors potentially enabling and limiting economic environment sustainability, but in fact, such conditions are more complicated, especially for different types of sharing economy practices and given the wide range of industries involved, and deeper and more comprehensive qualitative and quantitative research is needed to determine the optimal conditions. Regulatory research taking environmental sustainability as a regulatory goal is still relatively lacking compared to research focused on the traditional considerations.

This paper proposes overall principles and ideas for government regulators and the regulation of producers, consumers, and shared platform operators in the sharing economy and participation. According to the proposed regulatory ideas, taking shared bicycles as an example, relatively loose regulation should be implemented in the early-stage of bicycle-sharing industries. Although the phenomenon like random parking may violate existing laws and regulations, bicycle-sharing has 
brought about environmental benefits and potential for sustainability. With the scale expansion of the bicycle-sharing industry, the government should evaluate its environmental benefits through a specific framework. If it does bring environmental sustainability, government should adopt various economic or noneconomic incentives to encourage its development and formulate corresponding new regulations. For manufacturers of shared bikes, regulations should be implemented to make materials and components of bikes with durability, compatibility, and renewability to facilitate the sustainable use and recycling of bicycles. Platform operators of bike-sharing should do their best to maintain their bikes daily, restrict consumers through the incentives or punishment mechanisms to use bikes carefully and reasonably, and maintain the mobility of bike-sharing among different consumers. Through such regulatory principles and ideas, bicycle-sharing industry may have environmental benefits and environmental sustainability. Likewise, the proposed regulatory principles can be applied to other related sharing economy industries. Of course, for different segment industries, different specific regulations will be applied under proposed regulation principles.

However, how to implement these regulatory principles deserves further study. The study of the appropriate regulatory paths should also be combined with considerations of how to incorporate environmentally sustainable objectives into traditional regulations and - at the same time-grasp the different guiding principles of the traditional economic form in regulation.

Author Contributions: Conceptualization: X.L. and H.C.; Investigation: X.L.; Methodology: X.L.; Project administration: H.C.; Resources: X.L. and H.C.; Supervision: H.C.; Validation: X.L. and H.C.; Visualization: X.L.; Writing-original draft: X.L.; Writing—review \& editing: X.L. and H.C. All authors have read and agreed to the published version of the manuscript.

Funding: This research received no external funding.

Conflicts of Interest: The authors declare no conflict of interest.

\section{References}

1. The State Information Center. China's Annual Report on Development of Sharing Economy. 2019. Available online: http://www.sic.gov.cn/archiver/SIC/UpFile/Files/Default/20190301115908284438.pdf (accessed on 5 January 2020).

2. PricewaterhouseCoopers. Consumer Intelligence Series "The Sharing. Economy". Available online: https:/www.pwc.fr/fr/assets/files/pdf/2015/05/pwc_etude_sharing_economy.pdf (accessed on 5 January 2020).

3. Sdino, L.; Magoni, S. The Sharing Economy and Real Estate Market: The Phenomenon of Shared Houses. In Proceedings of the International Conference on Smart and Sustainable Planning for Cities and Regions, Bolzano Bozen, Italy, 22-24 March 2017; Springer: Cham, Switzerland, 2017; pp. 241-251.

4. Caprino, R.M.; De Mare, G.; Nesticò, A. Economic Evaluation and Urban Regeneration: A New Bottom-up Approach to Local Development Policies. In Seminar of the Italian Society of Property Evaluation and Investment Decision; Springer: Cham, Switzerland, 2016; pp. 379-390.

5. Belk, R. You are what you can access: Sharing and collaborative consumption online. J. Bus. Res. 2014, 67, 1595-1600. [CrossRef]

6. Botsman, R.; Rogers, R. What's mine is yours. In The Rise of Collaborative Consumption; Harper Business: New York, NY, USA, 2010.

7. Curtis, S.K.; Lehner, M. Defining the Sharing Economy for Sustainability. Sustainability 2019, $11,567$. [CrossRef]

8. Shang, Y.M. New progress in foreign sharing economy research. Inq. Econ. Issues 2018, 430, 182-189.

9. Verboven, H.; Vanherck, L. The sustainability paradox of the sharing economy. uwf UmweltWirtschaftsForum 2016, 24, 303-314. [CrossRef]

10. Ranjbari, M.; Morales-Alonso, G.; Carrasco-Gallego, R. Conceptualizing the sharing economy through presenting a comprehensive framework. Sustainability 2018, 10, 2336. [CrossRef]

11. Nissen, M. What Makes the Sharing Economy Sustainable; Aarhus University: Aarhus, Denmark, 2016.

12. Demailly, D.; Novel, A.S. The sharing economy: Make it sustainable. Studies 2014, 3, 14-30.

13. Hamari, J.; Sjöklint, M.; Ukkonen, A. The sharing economy: Why people participate in collaborative consumption. J. Assoc. Inf. Sci. Technol. 2015, 67, 2047-2059. [CrossRef] 
14. Heinrichs, H. Sharing economy: A potential new pathway to sustainability. Gaia 2013, 22, 228-231. [CrossRef]

15. Grinevich, V.; Huber, F.; Karataş-Özkan, M. Green entrepreneurship in the sharing economy: Utilising multiplicity of institutional logics. Small Bus. Econ. 2019, 52, 859-876. [CrossRef]

16. Vith, S.; Oberg, A.; Höllerer, M.A. Envisioning the 'sharing city': Governance strategies for the sharing economy. J. Bus. Ethics 2019, 159, 1023-1046. [CrossRef]

17. Brundtland, G.H. Our Common Future: The World Commission on Environment and Development; Oxford University Press: Oxford, UK, 1987.

18. Carter, C.R.; Rogers, D.S. A framework of sustainable supply chain management: Moving toward new theory. Int. J. Phys. Distrib. Logist. Manag. 2008, 38, 360-387. [CrossRef]

19. Wu, X.; Zhi, Q. Impact of Shared Economy on Urban Sustainability: From the Perspective of Social, Economic, and Environmental Sustainability. Energy Procedia 2016, 104, 191-196. [CrossRef]

20. Mi, Z.; Coffman, D.M. The sharing economy promotes sustainable societies. Nat. Commun. 2019, $10,1214$. [CrossRef]

21. Wang, C.A. Review of discussion on circular economy. Econ. Theor. Bus. Manag. 2004, V, 73-77.

22. Shi, Z.L.; Hou, X.M.; Bao, J.L. Analysis of the lack of motivation for cleaner production. Urban Environ. Urban Ecol. 2004, 5, 10-11.

23. del Mar Alonso-Almeida, M.; Perramon, J.; Bagur-Femenías, L. Shedding light on sharing ECONOMY and new materialist consumption: An empirical approach. J. Retail. Consum. Serv. 2020, 52, 101900. [CrossRef]

24. Zhang, H. The Impact of Shared Travel on the Taxi Industry: A Theoretical Perspective Based on Disruptive Innovation. Sci. Technol. Manag. Res. 2018, 1, 10-16.

25. Munkøe, M.M. Regulating the European Sharing Economy: State of Play and Challenges. Intereconomics 2017, 52, 38-44. [CrossRef]

26. Bonciu, F.; Balgar, A.C. Sharing Economy as a Contributor to Sustainable Growth, an EU Perspective. Rom. J. Eur. Aff. 2016, 16, 36.

27. Roszak, J.; Marechal, F. The Importance of Environmental Sustainability in the Decision to Participate in the Sharing Economy; Umeå University: Umeå, Sweden, 2017.

28. Leismann, K.; Schmitt, M.; Rohn, H. Collaborative Consumption: Towards a Resource-Saving Consumption Culture. Resources 2013, 2, 184-203. [CrossRef]

29. Richins, M.L. When wanting is better than having: Materialism, transformation expectations, and product-evoked emotions in the purchase process. J. Consum. Res. 2012, 40,1-18. [CrossRef]

30. Liu, Z.; Feng, J.; Liu, B. Pricing and service level decisions under a sharing product and consumers' variety-seeking behavior. Sustainability 2019, 11, 6951. [CrossRef]

31. Owyang, J.; Tran, C.; Silva, C. The Collaborative Economy; Altimeter: San Mateo, CA, USA, 2013.

32. Rowe, P.C. Beyond Uber and Airbnb: The Social Economy of Collaborative Consumption. Soc. Media Soc. 2017, 3, 2056305117706784. [CrossRef]

33. Frenken, K.; Schor, J. Putting the sharing economy into perspective. Environ. Innov. Soc. Transit. 2017, 23, 3-10. [CrossRef]

34. Schor, J.B.; Fitzmaurice, C.J. Collaborating and connecting: The emergence of the sharing economy. In Handbook of Research on Sustainable Consumption; Edward Elgar: Cheltenham, UK, 2015; p. 410.

35. Martin, C.J. The sharing economy: A pathway to sustainability or a nightmarish form of neoliberal capitalism? Ecol. Econ. 2016, 121, 149-159. [CrossRef]

36. Wirtz, J.; So, K.K.F.; Mody, M.A. Platforms in the peer-to-peer sharing. J. Serv. Manag. 2019, 30, 452-483. [CrossRef]

37. Böcker, L.; Meelen, T. Sharing for people, planet or profit? Analysing motivations for intended sharing economy participation. Environ. Innov. Soc. Transit. 2016, 23, 28-29. [CrossRef]

38. Nijland, H.; Meerkerk, J. Mobility and environmental impacts of car sharing in the Netherlands. Environ. Innov. Soc. Transit. 2017, 23, 84-91. [CrossRef]

39. Skjelvik, J.M.; Erlandsen, A.M.; Haavardsholm, O. Environmental Impacts and Potential of the Sharing Economy; Nordic Council of Ministers: Danish, Norwegian, Swedish, 2017.

40. Amasawa, E.; Shibata, T.; Sugiyama, H. Environmental potential of reusing, renting, and sharing consumer products: Systematic analysis approach. J. Clean. Prod. 2020, 242, 118487. [CrossRef]

41. Chen, Y.J.; Chen, H.M. Is Bike Sharing Really Green? Exploring the Resource and Environmental Impact of Bike Sharing from the Perspective of the Whole Life Cycle. Environ. Econ. 2018, 16, 62-65. 
42. Allen, D.; Berg, C. The Sharing Economy: How Over-Regulation Could Destroy an Economic Revolution; Institute of Public Affairs: Melbourne, Victoria, Australia, 2014.

43. Ranchordás, S. Does sharing mean caring: Regulating innovation in the sharing economy. Minn. J. Law Sci. Techol. 2015, 16, 413.

44. Jiang, D.X.; Wang, S.J. Legal regulation of the sharing economy. Soc. Sci. China 2017, 9, 141-162.

45. Cai, C.L. The rise of the sharing economy and the government's regulatory innovation. South China J. Econ. 2017, V36, 99-105.

46. Chen, Y.Z. Study on innovative and friendly regulation for the sharing economy. Manag. World 2016, 8, 176-177.

47. Lu, X.X. Sharing economy: Transaction cost minimization, institutional change and institutional supply. Soc. Sci. Front. 2016, 9, 51-61.

48. Etter, M.; Fieseler, C.; Whelan, G. Sharing Economy, Sharing Responsibility? Corporate Social Responsibility in the Digital Age. J. Bus. Ethics 2019, 159, 935-942. [CrossRef]

49. Cohen, M.; Sundararajan, A. Self-regulation and innovation in the peer-to-peer sharing economy. Univ. Chic. Law. Rev. Dialogue 2015, 82, 8 .

50. Ma, Q. Development status, bottlenecks and countermeasures of sharing economy in China. Mod. Econ. Res. 2016, 10, 20-24.

51. Yu, X.F.; Ren, G.H. On the moderate regulation of privacy risk in Internet economy platform-Taking the sharing economy environment as the basic background. Collect. Essays Financ. Econ. 2018, 234, 104-112.

52. Wen, Q.H. Changes and regulation of labor regulations in the sharing economy. Soc. Sci. Res. 2018, 236, 92-104.

53. Yuan, Y.J.; Liu, L. Environmental regulation and economic growth: A research based on different kinds of economic regulation. Econ. Rev. 2013, 1, 27-33.

54. Einav, L.; Farronato, C.; Levin, J.D. Peer-to-Peer Markets. NBER Work. Pap. 2015, 8, 615-635.

55. Leung, X.Y.; Xue, L.; Wen, H. Framing the sharing economy: Toward a sustainable ecosystem. Tour. Manag. 2019, 71, 44-53. [CrossRef]

56. Miller, S.R. First Principles for Regulating the Sharing Economy; Social Science Electronic Publishing: New York, NY, USA, 2015; pp. 147-202.

57. Kim, M.J. Benefits and Concerns of the Sharing Economy: Economic Analysis and Policy Implications. KDI J. Econ. Policy 2019, 41, 15-41.

58. Li, Y. Governing the sharing economy smartly: A tale of two initiatives in China. Public Policy Adm. 2019. [CrossRef]

59. Geissinger, A.; Laurell, C.; Öberg, C. How sustainable is the sharing economy? On the sustainability connotations of sharing economy platforms. J. Clean. Prod. 2019, 206, 419-429. [CrossRef] 